\title{
Legal regulation peculiarities of the implementation of educational and enlightenment projects as the direction of the information space formation of knowledge
}

\author{
Marina Alekseeva $^{1 *}$, Julia Isakova $^{1}$, Victor Linkin ${ }^{1}$ and Oksana Dyshekova ${ }^{2}$ \\ ${ }^{1}$ Don State Technical University, Rostov-on-Don, Russian Federation. \\ ${ }^{2}$ Russian State Customs Academy, Rostov Branch, Rostov-on-Don, Russian Federation.
}

\begin{abstract}
The article is devoted to the peculiarities of the legal analysis of the implementation of educational and enlightenment projects in terms of the information space formation. The aims of the work were to carry out the legal analysis of the terminology of the notions "educational project" and "enlightenment project" in the legal acts of regulation the mechanism of educational policy, justification of the necessity for unification of the approaches in the implementation of educational programs and development of the exact criteria of the evaluation for carrying out the educational and enlightenment projects in terms of information space of knowledge. The conducted analysis showed that the conditions for the functioning of the electronic informational and educational environment are created by numerous Internet projects, search systems, newsletters, forums, online consultations, audio-visual services, social services in the Web 2.0 format, user content and information resources (of public and scientific-methodological nature). The main types of educational projects implemented by means creating conditions for the information space formation of knowledge are identified: media and social educational projects (public media projects), enlightenment projects in the Internet space (enlightenment projects with the use of the possibilities of mass media communications, interactive enlightenment projects) and information enlightenment projects.
\end{abstract}

\section{Introduction}

In modern conditions, interest towards the innovation activity has gained the global spread through a new understanding of the notion "project", regarded as "a whole, completed cycle of productive (innovative) activity", a new branch of knowledge has appeared - "project

\footnotetext{
*Corresponding author: alekseeva80@yandex.ru
} 
management".

The terminology of the notions "educational project" and "enlightenment project" in legal acts of regulation the mechanism of their implementation is presented differently, and the educational policy requires unification of approaches in the realization of educational programs and working out of clear criteria for assessing of the realization of the educational and enlightenment projects in terms of the information space of knowledge. The traditional understanding of the notion "project" (from the Latin. projectus, word for word - thrown ahead), existing earlier, is a "developed plan of construction, the organization of something; preliminary text of any document; intention, plan".

The provision on the organization of project activity in the Government of the Russian Federation (approved by the Decree of the Government of the Russian Federation № 1288 of October 31,2018 ) determines that project activity includes the initiation, preparation, implementation and completion of projects. The main stages and steps of the project implementation phase are connected with the development and approval of draft acts of the Government of the Russian Federation, prepared within the framework of the federal project realization. Among the methods and means of the given phase, monitoring of the implementation of national projects and federal projects is emphasized. For the implementation of this method the information contained in the information system of project activity is used.

In accordance with the Model Law of the Interparliamentary Assembly of States of the Commonwealth of Independent States (the IAS CIS) "On Enlightenment Activities" (new edition) (2016) (hereinafter referred to as the Model Law on Enlightenment Activity), enlightenment activity includes a complex of different ideas for the enlightenment of population and planned actions for their implementation. Among the stages of enlightenment activity management enshrined in the Model Law, the "implementation of decisions" is emphasized, project activity includes the use of "various means and methods" [1].

In our country, innovative ideas of project training appeared at the beginning of the 20th century, and enlightenment of a humanistic and patriotic orientation has even more ancient historical traditions [2, P. 154-156]. That's why in modern conditions of updating the general historical experience for the civilizational way of development of Russia the notions "educational project" and "enlightenment project" are widely used in legal regulation in various areas of the spiritual, social and other spheres of society life [2, P. 1419].

At the same time, there are no legal definitions of the considered notions in the legislation, and the interpretation and clarification are required to understand their meaning. Taking into account all these factors, for example, based on the fact that a number of the legal acts indicate the implementation of educational projects in the form of "conferences, round tables, seminars, master classes, etc.", it is possible to conclude that an educational project is a form of training and organization of cognitive activity. Cultural and educational projects in the separate legal acts are considered as social cultural events.

More complete understanding of the content and correlation of the notions of "educational project" and "enlightenment project" is provided by the definition of notions on the subject of the regulation in the Federal Law of December 29, 2012 № 273-FL "On Education in the Russian Federation" (hereinafter - the Federal Law on Education) and in the Model Law on Enlightenment Activity.

In general, it should be noted that the terminology of the notions "educational project" and "enlightenment project" in the legal acts regulating the mechanism of their implementation is presented in different ways.

So, in the Federal Law on Education the terms, denoting the innovative role of the projects in ensuring the modernization and development of the education system, are 
mostly used. Other Federal laws and other normative legal acts of the Russian Federation regulating relations in the field of education contain mostly the terms denoting the content of activities to modernize and develop the education system. The most complete picture of this, for example, reflects the implementation of the priority national project "Education" and the state program of the Russian Federation "Development of Education" [3], which form the bases for the development of the education system in accordance with the Decree of the President of the Russian Federation of July 5, 2018 № 204 "On national goals and strategic objectives of the development of the Russian Federation for the period up to 2024”.

The term "enlightenment projects" in the Federal legislation practically does not reveal itself, despite the fact that the notion "enlightenment activity" is widely used in it. In the regional legislation, the use of the term is connected with the regulation of the activity of socially oriented uncommercial organizations for the provision of socially useful services, the implementation technology of which is often the realization of enlightenment projects. In subsidiary legislation acts, the term "enlightenment projects" is most widely used in the legal acts of the Government of the Russian Federation and in regulatory legal acts of the governing bodies. The implementation of cultural and enlightenment projects is considered as one of the means of achieving the indicators of the state program "Development of Culture" and the implementation of the national project "Culture", aimed at the solving the problems of the Decree of the President of the Russian Federation of June 07, 2018 № 204.

Systematization of the terminological basis of the legal concepts of "educational project" and "enlightenment project" ensures their classification on various grounds, including the totality of interrelated methods, ways and techniques of the subject activity, i.e. on implementation technologies.

The Federal law on education by the technologies of realization of educational programs defines "the network forms of their implementation", "distance educational technologies" and "electronic teaching".

In accordance with the Art. 16 of the Federal Law on Education in the implementation of educational programs with the application of electronic teaching and distance educational technologies, the conditions must be created for the functioning of the electronic information and educational environment, including electronic information and educational resources, a combination of information and telecommunication technologies, relevant technological means and providing mastering by students of educational programs in the full volume regardless of the students localization.

That is, the given norms of the Federal Law on Education meet the requirements of forming the information space of knowledge and allow to consider it and the main elements of its structure as the subject of the legal relations within the framework of educational programs realization with the application of electronic teaching and distance learning technologies.

The Federal Law on Education does not contain similar norms when regulating the network form of the implementation of educational programs. At the same time, for example, within the meaning of the norm in part 2 of article 13 of the current Federal law, the network form of educational programs implementation can be introduced by means of the usage of electronic teaching and distance learning technologies; the interpretation of the declared requirements in the Federal Law towards organization and implementation of educational programs with the application of the network form indicates that it should be carried out, including taking into account the provision of access to the electronic information and educational environment of the partner organizations, etc.

Nothing is also directly said in the Federal Law on Education and other federal laws containing norms regulating the relations in the sphere of education on the implementation of the educational projects in the considered context, i.e. based on the usage of information 
technologies and telecommunication networks.

At the same time, for example, according to the Part 3 of the Art. 20 of the Federal Law on Education, the innovative activity in the sphere of education is carried out in the form of projects and programs realization.

Federal Law of August 23, 1996 № 127-FL "On science and state scientific technological policy" contains the norm on "the innovative projects, including those directed towards the perspective development of the scientific organizations and educational organizations of higher education".

Federal Law of 4 November, 2014 № 327-FL "On Patron Activity" refers to "the implementation of priority programs of preservation of cultural properties and development of activity in the sphere of culture and education in the field of culture and art and the projects of such programs".

The regulation of the implementation of the network educational projects is more substantially presented in the legal acts of the Government of the Russian Federation and in the regulatory legal acts of the Federal Executive Body carring out the functions of the state policy generation and legal regulation in the sphere of education.

\section{Results and discussion}

The analysis of the regulatory acts in this area showed that the conditions for the functioning of the electronic information and educational environment are created by numerous Internet projects, search systems, newsletters, forums, online consultations, audiovisual services, social services in the "Web 2.0" format, user content, informational resources (of public and scientific-methodological nature), etc. All this allows to consider the implementation of the network educational projects as a direction of the formation of the information space of knowledge.

Discussion. According to the methodology of educational activity the completeness of the educational project cycle, implemented in a definite time sequence, is determined by three phases: design, technological and reflective. In each phase stages and steps, methods and means are distinguished. The technological phase of the project represents the practical implementation of the designed system by means of certain technologies, i.e. systems of forms, methods and means of solving the assigned tasks [4].

The content of all the above mentioned provisions of the current legislation confirms the correctness of the provisions of the methodology of educational activity in the point that "according to the composition, structure and subject area large projects are commonly referred to as programs" [4, P. 14] and that "in the network form of implementation the educational program can be considered either as part of the huge network project or as a separate network project "[9, P. 717].

So, for example, among specialists in the sphere of education the textbook "New Pedagogical and Information Technologies in the Education System" is widely known. The textbook is prepared by the assistants of the Institute of the Strategic Education Development (ISED) of the Russian Academy of Education edited by Professor E.S. Polat in 2002. The manual systematically presents the issues of application of the computer technologies in education, discloses the features of the organization and conduct of telecommunication educational projects. At the same time, the perspectives of the information technologies development to support education are presented in the given work only in terms of the organizational and technical aspect and they don't reflect the synergies of the information space of knowledge [4].

If this situation was acceptable for the time when the directions of the information society development in Russia were at the beginning of their determination. But for the present time of providing the conditions for the formation of a knowledge society in our 
country such position is not quite acceptable. So, for example, in the collections of the scientific papers of the participants of the last two annual scientific-practical conferencesexhibitions "Information Technologies in Education" in Rostov-on-Don more than three hundred abstracts were published. None of these abstracts touched upon the issues of the information space of knowledge formation directly.

The Concept of educational activity "Enlightenment for the Future", developed by the scientists of the International Institute of Management LINK (Learning International Network) (Zhukovsky) in 2016 is a systematic document of the theoretical and practical importance for the organization of educational work in Russia, according to its authors. The concept represents enlightenment projects as one of the forms of enlightenment activity, describes forms of the enlightenment activity on the basis of the application of web technologies and their possibilities for the development of enlightenment. However, the implementation of the enlightenment projects as a direction of the information space of knowledge formation in the Concept is not emphasized. The Concept indicates that "the formation of the enlightenment space that is not limited by a specific framework and of the system of participants communication in the enlightenment activity combining virtual and real forms of interaction" is one of the advantages the application of the modern web technologies in the enlightenment activity [5].

The analysis of the above given provisions allows to determine the main types of the enlightenment projects implemented by means creating the conditions for the information space of knowledge formation. They are: media-social enlightenment projects (public media projects), enlightenment projects in the Internet space (enlightenment projects with the use of the capabilities of mass media, interactive enlightenment projects) and information and enlightenment projects. Technologies for the implementation of media and social enlightenment projects (public media projects) are associated with the use of the services of the Internet, television, radio, other media, animation, etc.

An informational enlightenment project is aimed at collection the information about any object, phenomenon with the aim of its analysis, generalizing and presenting it to a wide audience. The result of the implementation of such a project, based on electronic communication channels, as a rule, is the creation of certain information resources and knowledge environment in the Internet space [6].

The realization of the emphasized enlightenment projects stipulates the use of such forms and means as electronic libraries and electronic resources (including subscription ones); remote access calls and electronic document delivery (book delivery); video conferences and webinars; enlightenment portals (sites); placement of various types of enlightenment information (including information based on multimedia and interactive technologies) for universal access to the Internet (audio and video materials, photo galleries and newsreels, virtual tours, exhibitions, presentations, interviews with experts, dialogues and discussions, and etc.)

The use of the above mentioned and other web technologies in the implementation of enlightenment projects ensures the formation of the unlimited enlightenment space and communication system of the participants of the enlightenment activity, the creation on this basis of the relevant information fields and information flows in the structure of the information space of knowledge.

\section{Conclusions}

Thus, the implementation of educational and enlightenment projects can be considered as the technological life phase of the cycle of the given projects, the content of which consists in the practical solution of the assigned tasks by means of certain technologies. The content of the legal regulation of the implementation of the educational and enlightenment projects 
also evidences this, despite the fact that its process and result reflect many legal terms that need to be systematized. In particular, the main technologies for the implementation of the educational projects are "network forms of their realization", "distance educational technologies" and "electronic teaching", the forms, methods and means of which create the conditions for the functioning of the electronic information and educational environment. Similar content is provided during the implementation of the enlightenment projects based on the use of various web technologies. All this allows us to consider the implementation of educational and enlightenment projects on the basis of the use of the information and communication technologies as a direction for the formation of the information space of knowledge. At the same time, in science there is still no conceptual awareness and systematic presentation of the experience of organization and carrying out of these types of activities, as well as legal regulation of arising on their basis legal relations.

Also, this is not ensured by the presence of a multitude of works on the issues of information technologies application in education and enlightenment and the conduct of the scientific and practical conferences on the given issues and the problems of solving them at the methodological level.

\section{References}

1. On approval of the state program of the Russian Federation "Development of education" (2017)

2. A.M. Novikov, D.A. Novikov, Educational project (methodology of educational) ("Egves", Moscow, 2004)

3. Zh.G. Timergaleeva, R.M. Timergaleev, O.V. Pulyaevskaya, Bulletin of Irkutsk State Technical University. 7(102), 242-243 (2015)

4. E.S. Polat, M.Yu. Bukharkina,M.V. Moiseeva, A.E. Petrov, New pedagogical and information technologies in the education system: textbook for students of higher educational institutions ("Academy", Moscow, 2008)

5. V.D. Orekhov, E.S. Komrakov, The concept of enlightenment activity "Enlightenment for the future" (IIM LINK, Moscow, 2016)

6. E.B. Vesna, A.I. Guseva, Modern problems of science and education: electronic scientific journal. 6, (2013) 